\title{
Factor Analysis of E-learning Services Quality
}

\author{
Xinglong Xie* \\ Economics \&Management Institute, Xi'an University of Technology Xi'an, China, P.Q.710048
}

\begin{abstract}
This paper aims to perform a factor analysis of e-learning service quality for providing valuable references and proposing strategies, which would advance successful e-training operations. This paper delineates services features and overviews current literature on e-education quality assessment. From e-learning attributes and the outlook of SSCE (services science, management, and engineering), the paper designs an indicator structure consisting of 10 criteria. Based on questionnaires, each indicator is given a certain value, and e-views is employed to calculate principal components. The paper finds six factors are crucial to measure of e-learning services quality for representing a $82.5 \%$ proportion in the total variance. Top three factors are ease of use, security, and reliability, indicating that network facilities, e-safety protection, and high-levels of instructing and punctual answering learner-raised questions after class, are leading prerequisites of maintaining superior e-educational quality. E-education suppliers should put efforts into these dimensions for providing quality e-training services.
\end{abstract}

\section{Introduction}

The rapid evolution of information technology has created new applications, such as e-banking, e-learning and e-health [1]. E-learning is a common application that is widely used in the educational sector [2]. The main objective of ICT is to reduce the limitations on time and location, in the context of higher education. It allows access to desired information, without limitations [3]. So, it fills the gap of traditional educational modes. Recently, this learning mode is taking on a swift upward trend, mainly driven by strong demand for new technology, knowledge and academic degrees of on-the-job individuals, increasing recognition of online diplomas, building of occupational and adult education networks.

*Corresponding author:long86886@aliyun.com
It is estimated that e-education for China will grow at annual $150 \%$ rate, averaging US\$ 1014.5US\$ in expenditures per capita, with an annual expanding capacity of market reaching US\$0.6087 Billion. Under this backdrop, quality for e-learning is increasingly emphasized as learners are required to become more active and self-constrained due to diminishing of instructors' dominating role, which exists in the traditional teaching activity. Otherwise e-education would fail to make the expected contribution to society. Traditional instruction wields restrictions a learner's time and space and indeed robs learning of the convenience of choosing the time to learn, which can even cause learners to lose the motivation to learn [4]. Web-based e-learning has been promoted in government institutions to improve 
national digital competitiveness. Additionally, some enterprises have successively introduced web-based e-learning as a platform for training employees, creating a shared learning environment and strengthening the professionalism and information-related competencies of employees [5].

Under swift development of e-learning, quality has triggered a great deal of attention from scholars, government and public as it is recognized as a lifeline of e-education. Large quantities of service quality evaluations are conducted on the foot indicators arising from experts, authorized organizations and academic institutes. To name but few, European Treasure Browser Quality Research Project, Development of a European service for Information on Research and Education, E-learning Courseware certification Standards, and Enforcing Regulating of E-colleges and Improving Instructing Quality(China). Regarding reference to determinants exercising effects on e-learning services quality, there is no universal conclusion but there exist generalized several schools of viewpoints: bi-factors referring to deliberated courses and superior learning resources for trainees, tri-factors meaning instructors, curriculums and education management, four elements covering teaching resources, technological facilities, educators and learners, and multiple-elements including objective and subjective dimensions. Thus, there have been no criteria over gauging of e-learning services quality inside China. It remains controversial on what factors should fall into the structure of services quality measurement for e-education. Determining these contributors is extremely significant and pressing to safeguarding e-training quality and driving the education into a scientific development track.

The aim of this paper is to contribute to the growing body of literature on e-learning by dealing with principal factors affecting e-learning services quality based on e-learners' perceived value. This paper can alleviate pitfalls existing in traditional teaching services quality assessment such as overlooking the role of trainees. Our analysis employs data stemming from 1052 questionnaires, which gives our study a uniqueness to other similar studies dedicated to examining e-educational services. We develop use of principal component and factor analysis to seek those factors which play a leading role in the e-learning services quality. Those factors could be a reference for other investigations measuring services quality related to e-education and act as guidance for companies or individuals that are engaged in e-teaching business. One contribution is to facilitate the current complex measurement of e-educational services by streamlining the structure bracing more variables and alleviating defects from linear regression like variable correlation.

\section{Literature review}

\subsection{Services and services science}

A service is an activity which has some element of intangibility associated with it, which involves some interaction with customers or with property in their possession, and does not result in a transfer of ownership. A change in condition may occur and production of the service may or may not be closely associated with a physical product. Services mainly features intangibility, heterogeneity, inseparability, and perishability.

Distinctive perspectives are used by scholars to explain services science (services science, management, and engineering (SSME)): (1) from the discipline perspective. SSME is a cross-multi discipline of computer science, operational research, industrial engineering, math, management science, decision-making, and law science. Spohrer defines SSME as a science which applies theories of science, management and engineering into jointly completing a specific lucrative task by a person, or an institution or a system with another person, another institution or another system. (2)From the systematic viewpoint, serving system is a major researched object in SSME. Spohrer points out that SSME resolves complicated practical problems through synthesizing various analysis methods from disciplines such as service science, management and engineering. (3) From the value-creating outlook. The role that SSME plays in services innovation and optimization during the course of value creating is brought to light. Bitner believes that SSME, through examining basic science, models, theories and their usage, resolves the problems of innovation, competition, and quality arising from serving courses to achieve value creation. (4)From contents in services, innovation and capability are underscored. Abe 
holds that SSME, through efficiently projecting production efficiency, quality, and performance of services, developing and repetitively using knowledge to optimize services, promotes innovation and productivity of services. IBM are credited with putting the SSME acronym together representing the cross disciplinary approach of Services Science, Management and Engineering while Cambridges Institute for Manufacturing and IBM also discussed development in the field in 2007.To sum up, services science is defined as an emerging discipline that aims to combine fundamental science and engineering theories, models and applications with facets of the management field, particularly knowledge, supply chain and change management, for and advancing service innovation and is becoming a key driver of socio-economic growth.

\subsection{Importance regarding e-learning}

As a learning model unrestricted by time or space, e-learning is a type of remote learning. In addition to integrating learning and the Internet, it also enables learners to develop their professional knowledge, to select the information they need, and to set the pace of their own learning. Learners can use the Internet to obtain educational content, and it is possible to extend e-learning via e-learning assistance and community knowledge-sharing systems. Through the Internet, e-learning allows digitized instructional materials to be quickly and efficiently transmitted, lowers production costs, and greatly lowers the time needed for learners to search for the educational content needed to engage in self-directed study. E-learning acts as the most cost-effective educational and training tool, enabling the learner to obtain abundant and diverse content quickly [6].Obstacles that are encountered during the process of e-learning can be discussed with teachers or peers through the Internet in a process of cooperative online learning, which enhances the interactive aspects of learning. Furthermore, the Internet accelerates the speed of updating educational content, enabling the learner to access new knowledge faster. Thus, e-learning has been viewed as an efficient learning technique.

\subsection{E-learning Service Quality Assessment}

For e-training, services quality assessment has aroused concern from academicians and produced much fruit. Quite representative are America's ASCI, Euripe's ECSI,SCCTB from Swede, and CNESI proposed by Chinese experts. Additionally, some scholars claimed that strong commitment fulfillment capacity and instructors' high qualification exert a great impact on the confidence and trust of learners. According to Charles and Paula, five dimensions stemming from SERVQUAL, are utilized to measure perceived quality of e-learning services. Having conducted an empirical analysis of learners' satisfaction degree, Qian(2009) found that perceptive services quality serves as a crucial determinant[7]. It is imperative that China need put efforts into promote web education systems in ease of use, practicality and stability. Jin, Shi and Zhen claimed that deficiency in learning time wields negative effects on customer satisfaction [8]. E-education services are reliant on five criteria including responsiveness and indicators for services quality differences are employed to investigate e-education analysis.

\section{Empirical analysis}

\subsection{Indicator framework}

Designing an indicator framework for assessing e-learning is aimed at satisfying online education ' $s$ specialized features, deriving learners of becoming armchair strategists, getting involved in various practical management activities, and access to data collection, for cultivating their management technique and skills, and improving their ability to analyze and tackle real problems. Hence, an indicator structure needs to give prominence to e-education's property, contemplate user needs, and serve as a reference to rating instructing quality at the same time. In view of deep exploration from scholars and achievements concerning e-education, following "objectivity, operability, supervisoryness, stability and popularization", this study, sets an indicator frame gauging e-learning services quality(table 1).

Table 1.Indicator structure

\begin{tabular}{|c|c|}
\hline \multirow{2}{*}{ Criteria/symbol } & Measure of services prior sales \\
\cline { 2 - 2 } & Sub-criteria \\
\hline
\end{tabular}




\begin{tabular}{|c|c|c|c|c|}
\hline $\begin{array}{l}\text { Ease of } \\
\text { Use/EU }\end{array}$ & Swift Website speed & $\begin{array}{l}\text { Convenience concerning course } \\
\text { inquiry and retracing }\end{array}$ & $\begin{array}{l}\text { Simplicity and easiness of } \\
\text { transaction procedures }\end{array}$ & $\begin{array}{l}\text { Explicit course information and } \\
\text { knowledge }\end{array}$ \\
\hline Tangibility/TA & $\begin{array}{l}\text { Superior, perceived } \\
\text { image and concise } \\
\text { name }\end{array}$ & & Rational page layout & $\begin{array}{l}\text { Audio-visional and trouble-free } \\
\text { steering and service center }\end{array}$ \\
\hline Interaction /INC & $\begin{array}{l}\text { Clients interact with } \\
\text { learners to offer } \\
\text { help. }\end{array}$ & & & \\
\hline Security/SE & Safe deal & Privacy is preserved & $\begin{array}{l}\text { Accountable data in the } \\
\text { website }\end{array}$ & \\
\hline Reliability/RE & $\begin{array}{l}\text { Clients are } \\
\text { trustworthy }\end{array}$ & Accurate course contents & & \\
\hline \multirow[t]{2}{*}{ Branding/BR } & $\begin{array}{l}\text { Credibility and } \\
\text { prestige }\end{array}$ & Public praise & & \\
\hline & Services after sales & & & \\
\hline Reliability/RE) & $\begin{array}{l}\text { Complete } \\
\text { curriculum } \\
\text { resources }\end{array}$ & $\begin{array}{l}\text { Regularly update schooling } \\
\text { resources }\end{array}$ & $\begin{array}{l}\text { Answer questions at the } \\
\text { reasonable time }\end{array}$ & $\begin{array}{l}\text { Play E-lecturing documents for } \\
\text { audiences affluently and stably }\end{array}$ \\
\hline $\begin{array}{l}\text { Validity for } \\
\text { schooling } \\
\text { resources/VSR }\end{array}$ & $\begin{array}{l}\text { Teacher competence } \\
\text { meets educational } \\
\text { demand }\end{array}$ & $\begin{array}{l}\text { High quality textbooks and } \\
\text { supporting materials }\end{array}$ & $\begin{array}{l}\text { Contents are accurate, } \\
\text { without errors or redundant } \\
\text { messages }\end{array}$ & $\begin{array}{l}\text { Lessons can be showed online or } \\
\text { offline }\end{array}$ \\
\hline Interest/INT & $\begin{array}{l}\text { Contents are } \\
\text { delightful, } \\
\text { productive to } \\
\text { improving creativity } \\
\text { and imagination }\end{array}$ & $\begin{array}{l}\text { Designing of learning stages is } \\
\text { interesting, beneficial to raising } \\
\text { academic records }\end{array}$ & $\begin{array}{l}\text { Website functions are } \\
\text { vividly designed, facilitating } \\
\text { self-tests or looking up data }\end{array}$ & \\
\hline $\begin{array}{l}\text { Responsiveness/R } \\
\text { ES }\end{array}$ & $\begin{array}{l}\text { Customer services } \\
\text { providers are ready } \\
\text { to tackle problems } \\
\text { for students. }\end{array}$ & $\begin{array}{l}\text { Amicably deal with complaints } \\
\text { lodged by learners }\end{array}$ & $\begin{array}{l}\text { Assist trainees to carry out } \\
\text { matters such as dropping out } \\
\text { and canceling a course }\end{array}$ & $\begin{array}{l}\text { Correct homework and respond to } \\
\text { questions from learners }\end{array}$ \\
\hline Solicitude/SO & $\begin{array}{l}\text { Offer } \\
\text { examination-related } \\
\text { information } \\
\text { including reminding } \\
\text { services }\end{array}$ & $\begin{array}{l}\text { Provide online-technological } \\
\text { support to take up problems } \\
\text { emerging during the lesson- } \\
\text { listening course }\end{array}$ & $\begin{array}{l}\text { Can supply trainees with } \\
\text { customized services }\end{array}$ & $\begin{array}{l}\text { Offer a complaint mechanism to } \\
\text { unwind issues confronting } \\
\text { customers. }\end{array}$ \\
\hline
\end{tabular}

Table 2. Profile of questionnaire respondents

\begin{tabular}{|c|c|}
\hline Classification & Sample distribution \\
\hline gender & Males accounting for $62.9 \%$; female accounting for $37.1 \%$ \\
\hline age distribution $(\%)$ & $\begin{array}{l}\text { Samples between } 20 \text { and } 29 \text { years } 58.1 \% ; 30-39 \text { years } 33.4 \% ; 40-49 \text { years } 8.0 \% ; 50-59 \text { years } 0.5 \% ; 60 \text { years or above } \\
0.1 \%\end{array}$ \\
\hline education background & $\begin{array}{l}\text { Undergraduate } 5.7 \% \text {; bachelor } 41.4 \% \text { (four years); bachelor(starting from undergraduate) } 50.4 \% \text {; professional master } \\
0.4 \% \text {; second bachelor } 1.5 \% \text {; academic master } 0.4 \% \text {; doctor } 0.2 \%\end{array}$ \\
\hline e-education time & One year below $21.4 \%, 2-3$ years $70.9 \% ; 4-5$ years $6.4 \% ; 6$ years above $1.3 \%$ \\
\hline
\end{tabular}

Table 3.Indicator value 


\begin{tabular}{|c|c|c|c|c|c|c|c|c|c|c|}
\hline If an indicator is & \multicolumn{2}{|c|}{ very unimportant } & \multicolumn{2}{|c|}{ unimportant } & \multicolumn{2}{|l|}{ uncertain } & important & \multicolumn{3}{|c|}{ absolutely important } \\
\hline Its value & \multicolumn{2}{|c|}{1} & \multicolumn{2}{|c|}{2} & \multicolumn{2}{|l|}{3} & 4 & \multicolumn{3}{|c|}{5} \\
\hline Criteria & EU & TA & INC & $\mathrm{SE}$ & REL & $\mathrm{BR}$ & VSR & INT & RES & $\mathrm{SO}$ \\
\hline Cronbach Alpha & 0.91 & 0.87 & 0.90 & 0.91 & 0.90 & 0.90 & 0.90 & 0.90 & 0.86 & 0.95 \\
\hline
\end{tabular}

Table 5. KMO and Bartlett testing

\begin{tabular}{|l|l|l|}
\hline Kaiser-meyer-Olkin & & 0.80 \\
\hline Bartlett & Approximate chi square & 226.5 \\
\hline & Sig. & 0.000 \\
\hline
\end{tabular}

Table 6. Results of principal analysis

\begin{tabular}{|c|c|c|c|c|c|c|c|c|c|}
\hline \multicolumn{10}{|c|}{ Explained total variance } \\
\hline \multirow[t]{2}{*}{ Component } & \multicolumn{3}{|c|}{ Initial eigenvalue } & \multicolumn{3}{|c|}{ Extracting sum of squares loading } & \multicolumn{3}{|c|}{ Rotating sum of squares loading } \\
\hline & Total & Variance & Accumulative & Total & Variance & Accumulative & Total & Variance & Accumulative \\
\hline $\mathrm{F} 1$ & 4.08 & $40.8 \%$ & $40.8 \%$ & 4.08 & $40.8 \%$ & $40.8 \%$ & 2.32 & $23.2 \%$ & $23.2 \%$ \\
\hline $\mathrm{F} 2$ & 2.08 & $20.8 \%$ & $61.6 \%$ & 2.08 & $20.8 \%$ & $61.6 \%$ & 1.25 & $12.5 \%$ & $35.7 \%$ \\
\hline $\mathrm{F} 3$ & 0.91 & $9.1 \%$ & $70.7 \%$ & 0.91 & $9.1 \%$ & $70.7 \%$ & 1.24 & $12.4 \%$ & $48.1 \%$ \\
\hline F4 & 0.68 & $6.8 \%$ & $77.5 \%$ & 0.68 & $6.8 \%$ & $77.5 \%$ & 1.23 & $12.3 \%$ & $60.4 \%$ \\
\hline F5 & 0.6 & $6.0 \%$ & $83.5 \%$ & 0.6 & $6.0 \%$ & $83.5 \%$ & 1.11 & $11.1 \%$ & $71.5 \%$ \\
\hline F6 & 0.51 & $5.1 \%$ & $88.6 \%$ & 0.51 & $5.1 \%$ & $88.6 \%$ & 1.10 & $11.0 \%$ & $82.5 \%$ \\
\hline
\end{tabular}

Table 7. Matrix for factor loadings

\begin{tabular}{|c|c|c|c|c|c|c|}
\hline \multirow[t]{2}{*}{ Criteria } & \multicolumn{6}{|c|}{ Principal Component } \\
\hline & $\mathrm{F} 1$ & $\mathrm{~F} 2$ & F3 & F4 & F5 & F6 \\
\hline EU & 0.79 & 0.1 & 0.63 & -0.06 & -0.11 & 0.08 \\
\hline $\mathrm{TA}$ & 0.63 & 0.21 & -0.01 & 0.40 & 0.23 & 0.23 \\
\hline INC & 0.05 & 0.03 & 0.16 & 0.26 & 0.81 & 0.22 \\
\hline SE & 0.33 & 0.96 & 0.15 & 0.02 & 0.02 & 0.01 \\
\hline REL & 0.1 & 0.1 & 0.83 & 0.03 & 0.05 & 0.17 \\
\hline VSR & 0.02 & 0.43 & 0.1 & 0.89 & 0.05 & 0.09 \\
\hline RES & 0.11 & 0.29 & -0.05 & 0.22 & 0.89 & -0.03 \\
\hline $\mathrm{SO}$ & 0.15 & 0.02 & 0.16 & 0.21 & 0.08 & 0.65 \\
\hline INT & 0.13 & 0.01 & 0.17 & 0.69 & 0.26 & 0.21 \\
\hline BR & 0.42 & 0.12 & 0.17 & 0.12 & 0.09 & 0.05 \\
\hline
\end{tabular}

Table 8. Factor naming

\begin{tabular}{|c|l|l|l|l|l|}
\hline Factor & \multicolumn{1}{|c|}{1} & 2 & 3 & 4 & 5 \\
\hline Title & easy utilization & security & reliability & validity & responsiveness \\
\hline
\end{tabular}

\subsection{Data availability}

We made a survey of service quality to customers in March, April, October, and December of 2016, issuing 1200 questionnaires(see table 2), in which questions are formulated thanks to a 5-level Likert scale(see table 3), and getting back 1052. EXCEL is adopted for calculation. According to questionnaires, we summarize, process, and transform information into data calculating the value of an indicator. By means of e-views 6.0, the paper conducts factor analysis, which principal component analysis mixes a group of certain related initial variables into a set of irrelevant indicators through mathematical transformation with a view to obtaining linear combinations, which retain information as much as 
included in the primary variables. The primary step is to test variable correlation, then followed by principal analysis, and finally factors are determined which play critical part in e-study services quality measurement. Note that table Tables 4 and 5 register the result concerning questionnaire reliability and $\mathrm{KMO}$ and Bartlett testing respectively. Coefficient matrix eigenvalue, contribution and accumulative contribution are reported in table 6 , the factor loadings matrix table 7 , and factor names in table 8 .

\subsection{Discussion}

Table 4 demonstrates that the Cronbach Alpha coefficient for each criterion, the maximum topping 0.91 and the minimum at 0.87 , all, is in excess of 0.8 , implying that there is a high reliability for the designed questionnaire. Validity test must be conducted to confirm whether the factor approach is fit for the question in this study. To this end, we resort to the exploratory factor, voicing that the higher KMO, the more common factors among variables and the more suitable the factor methodology will be. If KMO exceeds 0.7 , the approach of factor analysis will be reviewed as appropriate. It can be found from table $\mathrm{V}$ that the relationship among variables is suitable to be examined through the way with the value for KMO above 0.80 and the significant linear connection between indicators implied by Barlett testing. Inter-variable relevance must be investigated to certify whether these variables have a certain dependency relationship, whereby finding out their correlation both degree and direction. In order to achieve this aim, various ways have been utilized in literature, in which Pearson correlation test receives wide-spread attention and usage. In this study, we also depend on Pearson to examine the correlation among ten indicators of gauging e-study services quality. The results show that there exists a significant positive linkage between two dimensions at the $5 \%$ level, for example, ease of use and tangibility, or security or reliability, validity of learning resources and solicitude. All this dictates that principal component analysis is suitable to be applied into dealing with services quality regarding e-learning.

Table 6 reveals that the cumulative variance of the cumulative eigenvalue for six former factors making up $82.5 \%$ of total variance, thus they are identified as principal components. As a result, ten original indicators can be shrunken into six main factors. Table 7 exhibits factor loadings after Kaiser rotation. Obviously, ease of use has the largest loading (0.79) in the first common factor, so the first factor is termed as the easy utilization factor. In the same token, factors are named security, reliability, learning resources' validity, responsiveness, and solicitude due to the largest loading in its own principal component, accordingly. Each of these factors represents a more definite economics meaning. Hence, gauge of e-learning services quality can be generalized into six major factors (see table 8). The loading for interaction comes in at $0.05,0.03,0.16,0.26,0.81$, and 0.22 in the six main factors, separately, and this displays interaction is mainly explained by easy responsiveness and solicitude factors, especially dominant effects by timely settlement of problems for learners.

\section{Conclusion and proposal}

The contribution of this paper is to provide an evaluation of services quality in e-learning. We extend existing literature via dealing with the principal components that mainly affect e-education services and thereby identifying the most significant factors shaping the services quality of e-education. Data are calculated grounded on answers from 1052 respondents, allowing us glean a broad range of new insights into e-learning services quality.

- The most important factor confirmed by its loading of 0.79 is easy utilization for e-learning services, demoting unhindered page linkage and strong searching functions, vigorously driving learners to carry out studying and related activities such as consulting curse-connected contents, instruction purposes, instructor resources, and supplement services. Thus, network facilities must be superior, assuring fresh information technology of being putting into use in the whole e-training process, updating teaching contents and supplying frontier knowledge dynamics.

- Factor security has evolved into anther critical element for e-educational quality with the loading reaching 0.96 and this suggests that one company would obtain access to the market if it provides safety and privacy guaranteeing for e-customers technologically and legally. 
-With reference to factor reliability, it plays an important role in improving e-training quality for its loading hitting 0.83 . Customers may not materially be benefited from purchasing an educational service commodity, for which production and consumption go side by side and this requires learner involvement and lecturer-student interaction. Otherwise, there would be no expected performance to be achieved. So, instructors should be equipped with ability to exactly fulfill commitments made. Additionally, strategies such as course updating and punctual offering answers to student-raised problems need to be put into effects for promoting e-learning quality improvement.

- Factor validity with a 0.89 loading displays professional competence and working spirit of instructors are the primary concern of e-learners. The loading of factor responsiveness at 0.89 shows e-students' learning process supervision from e-organizations and assuring trainees of obtaining access to answers to questions stand out for e-education services quality betterment. Concerning the solicitude factor, it also plays an important part in the measurement of e-learning services quality with its loading valued at 0.65 . It can be taken as the ability to willingly offer aid and enable to furnish just-in-time services for customers, for example, customized training. Thus, it is necessary and imperative for e-schools to build an effective system of supporting learning, bringing in a more meticulous and benevolent e-education, in which learners are centered.

Our results provide valuable insights into building and maintaining superior e-learning services:

- Initially, e-education suppliers ought to focus attention on web technology improvement as high qualify services depend on information telecommunications facilities and lay higher requirements on system environments, schooling platforms, software instrument and various management mechanisms. These technical infrastructures must be benign enough to guarantee successful teaching fulfillment, which can provide all prerequisites including independent and sufficient IP addresses and names, valid schooling information, managerial functions of users, and stability in net-work system operation. Furthermore, web technology, instructors' teaching techniques, and media communications should be integrated into a whole one to achieve the optimal result.

- e-educational schools must develop an advantage in the branch of learning or cooperate with those intuitions, which have an advantage in the regarding, or co-develop e-courses along with these organizations. As for launching a new major, it should be based on preponderant specialties. Moreover, lifelong-education must be the primary concern for e-lecturers themselves with substantial innovative skills and knowledge emerging by constant development of information technology, to allow their lectured knowledge to satisfy economic reality.

\section{Acknowledgment}

The authors are thankful to the financial aid from Shaanxi's fund program No.2015KRMO98.

\section{References}

[1] A. Y. Alsabawy, A.Cater-Steel, J.Soar, Determinants of perceived usefulness of e- learning systems, Computers in Human Behavior, 64, 2016,843-858.

[2]A. K. M. N. Islam, E-learning system use and its outcomes: moderating role of perceived compatibility, Telematics and Informatics,33, 2016,48-55,2016.

[3] A.Althunibat, Determining the factors influencing students' intention to use m-learning in Jordan higher education, Computers in Human Behavior, 52, 2015,65-71, 2015.

[4] H.R.Chen, H.L.Huang, User acceptance of mobile knowledge management learning system:design and analysis, Educational Technology \& Society, 13, 2010,70-77.

[5]S. Sridhar, S.E-government - a proactive participant for e-learning in higher education, Journal of American Academy of Business, vol.7, 2005, 258-268.

[6] A. Powell, M. Barbour, An examination of government policies for e-learning in New Zealand's secondary schools, Journal of Open, Flexible and Distance Learning, 5, 2011,75-89.

[7] X.Q. Qian, Empirical analysis of students' degree of satisfaction of e-education services quality, Distance Education in China, 7, 2009, 57-60.

[8]L.W. Jin, Zh.P. Shi, Q.H. Zhen, On factors affecting learners' degree of e-education satisfaction, Beijing Radio and TV University Journal, 2,2015, 49-52. 